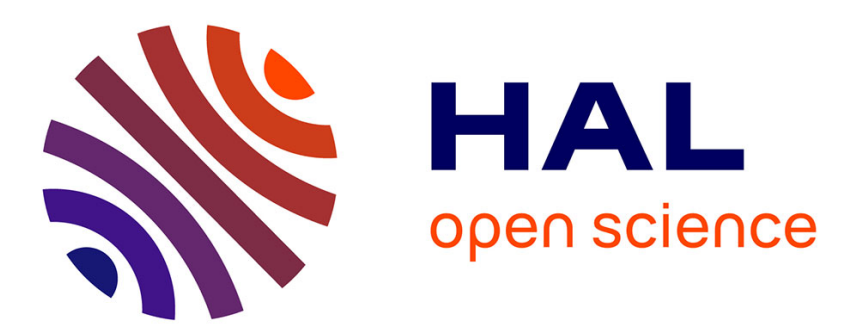

\title{
Microbial electrolysis cell (MEC): A step ahead towards hydrogen-evolving cathode operated at high current density
}

Raphaël Rousseau, Françoise Ketep, Luc Etcheverry, Marie-Line Délia-Dupuy, Alain Bergel

\section{To cite this version:}

Raphaël Rousseau, Françoise Ketep, Luc Etcheverry, Marie-Line Délia-Dupuy, Alain Bergel. Microbial electrolysis cell (MEC): A step ahead towards hydrogen-evolving cathode operated at high current density. Bioresource Technology Reports, 2020, 9, pp.100399. 10.1016/j.biteb.2020.100399 . hal02489337

\section{HAL Id: hal-02489337 https://hal.science/hal-02489337}

Submitted on 24 Feb 2020

HAL is a multi-disciplinary open access archive for the deposit and dissemination of scientific research documents, whether they are published or not. The documents may come from teaching and research institutions in France or abroad, or from public or private research centers.
L'archive ouverte pluridisciplinaire HAL, est destinée au dépôt et à la diffusion de documents scientifiques de niveau recherche, publiés ou non, émanant des établissements d'enseignement et de recherche français ou étrangers, des laboratoires publics ou privés. 


\section{OATAO \\ Open Archive Toulouse Archive Ouverte}

\section{Open Archive Toulouse Archive Ouverte}

OATAO is an open access repository that collects the work of Toulouse researchers and makes it freely available over the web where possible

This is an author's version published in: http://oatao.univ-toulouse.fr/25512

Official URL : https://doi.org/10.1016/j.biteb.2020.100399

\section{To cite this version:}

Rousseau, Raphaël柠 and Ketep, Françoise $\leftrightarrows$ and Etcheverry, Luc $\leftrightarrows$ and Délia, Marie-Line step ahead towards hydrogen-evolving cathode operated at high current density. (2020) Bioresource Technology Reports, 9. 1-9. ISSN 2589-014X

Any correspondence concerning this service should be sent to the repository administrator: tech-oatao@listes-diff.inp-toulouse.fr 


\title{
Microbial electrolysis cell (MEC): A step ahead towards hydrogen-evolving cathode operated at high current density
}

\author{
Raphaël Rousseau, Stéphanie F. Ketep, Luc Etcheverry, Marie-Line Délia, Alain Bergel* \\ Laboratoire de Genie Chimique, Université de Toulouse, CNRS, INP, UPS, Toulouse, France
}

Keywords:

Hydrogen

Saline medium

Microbial electrochemical technology

Microbial fuel cell

Bioelectrochemical system

\begin{abstract}
A B S T R A C T
A microbial electrolysis cell (MEC) $6 \mathrm{~L}$ in volume was designed with the objective of maximizing the current density at the cathode. The highly saline electrolyte $\left(\mathrm{NaCl} 45 \mathrm{~g} \cdot \mathrm{L}^{-1}\right)$ led to a low ohmic resistance, of $0.10 \Omega$, and made it possible to maintain current density of around $50 \mathrm{~A} \cdot \mathrm{m}^{-2}$ for weeks, with peak values up to $90 \mathrm{~A} \cdot \mathrm{m}^{-2}$ for hours. This was the highest current density reached in a MEC prototype so far. The gas outlet contained at least $66 \% \mathrm{H}_{2}$, which gave a hydrogen flow rate up to $650 \mathrm{Ld}^{-1} \mathrm{~m}^{-2}$ of cathode surface area. The energy and thermal yields were discussed. A numerical mass balance model was designed, which explained the value of the anode Faradaic yield above $100 \%$ and pointed out new issues related to high current density operation. In particular, it was shown that, at high current density, carbonate deposit can impact the gas composition.
\end{abstract}

\section{Introduction}

Microbial electrolysis proposes an innovative route for converting electrical energy to chemical energy in the form of hydrogen or methane. The concept of microbial electrolysis cells (MECs), first proposed in 2005 (Liu et al., 2005; Rozendal et al., 2006), is to couple a microbial anode with a hydrogen-evolving cathode. In comparison to conventional water electrolysis, the oxidation of water at the anode is replaced by the oxidation of low-cost organic compounds, which is made possible by the microbial anode (Kadier et al., 2014; Pandey et al., 2016; Pant et al., 2010). The equilibrium cell voltage of an MEC, $0.123 \mathrm{~V}$ in standard conditions, is thus considerably lower than that of water electrolysis, equal to $1.23 \mathrm{~V}$. On the basis of thermodynamics, the electrical power consumed by an MEC should be lower than that consumed by water electrolysis (Rousseau et al., 2020).

In spite of huge research efforts, the attempts to scale up to largesized MECs have encountered great difficulties (Escapa et al., 2015). Most MEC pilots with volumes of at least several litres have operated with very low current density, $<1 \mathrm{~A} \cdot \mathrm{m}^{-2}$ (Baeza et al., 2017; Brown et al., 2014; Chen et al., 2019; Cusick et al., 2011; Escapa et al., 2015; Gil-Carrera et al., 2013b, 2013c, 2013a; Heidrich et al., 2014, 2013; Luo et al., 2017; Sugnaux et al., 2017). One of the reasons for such poor performance was the usual choice to develop MEC pilots for wastewater treatments. Wastewaters have very low ionic conductivity, commonly of the order of $0.2 \Omega \cdot \mathrm{m}^{-1}$, sometimes less (Oliot et al., 2016). Scaling up an electrochemical process with such electrolytes is a very tough challenge (Oliot et al., 2017). Slightly higher current density, of 1.75 $\mathrm{A} \cdot \mathrm{m}^{-2}$, has been obtained with a specific effluent, pig slurry, which ensured higher ionic conductivity $\left(2.6 \mathrm{~S} \cdot \mathrm{m}^{-1}\right)$, with added acetate as the substrate (San-Martín et al., 2019). Using a synthetic medium with acetate has been necessary to increase the current density to $10 \mathrm{~A} \cdot \mathrm{m}^{-2}$ (Guo et al., 2017). To the best of our knowledge, in the context of MEC pilots of several litres, the highest current densities of $9.2 \mathrm{~A} \cdot \mathrm{m}^{-2}$, with peak value of up to $42.5 \mathrm{~A} \cdot \mathrm{m}^{-2}$ (with respect to the cathode surface area), have been reached by using a saline electrolyte (35 g/L NaCl), which ensured an ionic conductivity of $9 \mathrm{~S} \cdot \mathrm{m}^{-1}$ (Carmona-Martinez et al., 2015).

The purpose of the present study was to design an MEC pilot that produced the highest possible current density at the cathode. This optimization criterion was chosen because it corresponded to the highest possible hydrogen flux per cathode surface area.

It has recently been highlighted that the cathode current density, or the hydrogen production rate related to the cathode surface area, is the essential parameter to be maximised if the objective is to boost MEC technology towards commercial interest (Rousseau et al., 2020). This is also the essential parameter to be considered to compare different technological options, as it is the case for any electrochemical process (Wendt and Kreysa, 1999). Actually, volumetric hydrogen production rates are often reported and used for comparison of different devices in the literature devoted to MEC, but using this parameter is not scientifically supported and may lead to wrong conclusions (Rousseau et al., 2020). For this reason, according to common rule of electrochemical

\footnotetext{
* Corresponding author.

E-mail address: alain.bergel@toulouse-inp.fr (A. Bergel).
} 
engineering, maximizing the cathode current was the essential objective of this study.

A volume of $6 \mathrm{~L}$ was chosen as a first pilot step, i.e. around one order of magnitude above conventional laboratory cells. Then, all choices concerning operating conditions and reactor design were made in this single aim: to improve the cathode current density. No choice of application sector was made a priori. Optimal conditions were thus sought without the influence of a ny constraint related to an intended application domain and were notably free from the detrimental conditions related to domestic wastewater treatment.

In this framework, halotolerant microbial anodes were chosen because they can operate in electrolytes with high ionic conductivity (Grattieri and Minteer, 2018). In particular, microbial anodes formed from salt marsh inoculum have produced current densities up to 85 $\mathrm{A} \cdot \mathrm{m}^{-2}$ in well-controlled lab conditions (Rousseau et al., 2014, 2013). They have shown optimum performance in solutions containing $45 \mathrm{~g} \cdot \mathrm{L}^{-1} \mathrm{NaCl}$, with ionic conductivity of $10.4 \mathrm{~S} \cdot \mathrm{m}^{-1}$.

To reach the objective of the highest possible cathode current density, the MEC was designed with coaxial electrodes: external graphite felt anode and an internal stainless steel cathode. The coaxial architecture with the cathode at the core concentrated the current line on the cathode, which had a smaller surface area than the anode, and thus favoured high current density at the cathode.

The anode was made of graphite felt because this structure had already been successfully used with the salt marsh microbial anode chosen here. All microbial anodes require MECs to work at $\mathrm{pH}$ values near neutrality. In such conditions, the conventional catalysts for hydrogen evolution at the cathode, notably platinum, lose their catalytic properties. Consequently, the cathode was made of stainless steel, which is known to be appropriate for MEC cathodes (Selembo et al., 2009). Moreover, near neutral pH, stainless steel in association with weak acids is involved in a catalytic pathway of hydrogen evolution (Da Silva et al., 2004; Munoz et al., 2010; Roubaud et al., 2018).

It was chosen to run the MEC by controlling the potential applied to the anode vs. a reference electrode because the potential has been shown to impact the characteristics and performance of the microbial anode (Rousseau et al., 2016). This solution could not be scaled up to industrial level, where galvanostatic control is preferred. However, galvanostatic control is not suitable for a microbial anode because, should the reaction catalysed by the micro-organisms be deficient, the anode would start to oxidize water and/or chlorides to ensure the imposed current (Rousseau et al., 2020). The production of oxygen and/or chlorine at the anode surface would definitively destroy the electroactive biofilm. Consequently, in the current state of the art, control of the potential applied to the anode appeared as the best alternative to maximize current density (Rimboud et al., 2014). Another solution will have to be found to scale the process up for industrial applications, using the cathode as a pseudo-reference, for example.

The cathode current densities reported for MEC pilots so far are so low compared to those reached by water electrolysis cells (for instance, a proton exchange membrane (PEM) electrolysis cell can reach 20,000 $\mathrm{A} \cdot \mathrm{m}^{-2}$ ) that it seems urgent to raise the current density levels in order to promote the technology and provide arguments for continuing to support the research efforts. We hope this work will give some elements going in this direction.

\section{Materials and methods}

\subsection{MEC design}

The MEC was a polycarbonate cylinder of $40 \mathrm{~cm}$ height and $14 \mathrm{~cm}$ internal diameter, with a total volume of $6 \mathrm{~L}$. It was equipped with a $12 \mathrm{~mm}$ thick graphite felt anode (RVG 4000, Mersen, France), $20 \mathrm{~cm}$ high and $40 \mathrm{~cm}$ wide (surface area $800 \mathrm{~cm}^{2}$ ), sandwiched between two cylindrical titanium grids used as current collectors. The anode was placed against the reactor wall. In the centre, the cathode was a $2 \mathrm{~cm}$ diameter, 254 SMO stainless steel pipe (Outokumpu, Sweden). The volume of the electrolyte, $5.25 \mathrm{~L}$, filled the reactor to a height of $35 \mathrm{~cm}$, so the cathode surface area exposed to the electrolyte was $220 \mathrm{~cm}^{2}$. The reactor was surrounded with an external water jacket to maintain the temperature at $40{ }^{\circ} \mathrm{C}$. The anode was polarized at $0.1 \mathrm{~V}$ vs. a saturated calomel reference electrode ( $0.24 \mathrm{~V} / \mathrm{SHE}$, Radiometer), which was set in the lid of the reactor, with a Biologic potentiostat.

Unless otherwise stated, current densities are expressed with respect to the surface area of the cathode $\left(220 \mathrm{~cm}^{2}\right)$. The Faradaic yield related to acetate oxidation at the anode was calculated as the ratio of the charge that circulated in the electrical circuit during a given period to the charge that could be produced by the oxidation of the amount of acetate consumed during the same period, according to reaction (1):

$\mathrm{CH}_{3} \mathrm{COO}^{-}+2 \mathrm{H}_{2} \mathrm{O} \rightarrow 2 \mathrm{CO}_{2}+7 \mathrm{H}^{+}+8 \mathrm{e}^{-}$

Sediments collected from a salt marsh (Mediterranean Sea, Gruissan, France) were used as the inoculum, at $5-10 \% \mathrm{v} / \mathrm{v}$ inoculum ratio. The electrolyte was based on Starkey medium (detailed composition published elsewhere (Rousseau et al., 2013)) supplemented with $\mathrm{NaCl} 45 \mathrm{~g} \cdot \mathrm{L}^{-1}$ and various concentrations of sodium acetate used as the substrate. The conductivity of the final solution was $10.4 \mathrm{~S} \cdot \mathrm{m}^{-1}$, and its $\mathrm{pH}$ was 7.5.

\subsection{Analytical procedures}

The reactor was hermetically sealed and the gas composition was analysed in the outlet stream by micro gas chromatography ( $\mu \mathrm{CPG}$ 490GC, Agilent). A zeolite molecular sieve column was used to measure the $\mathrm{H}_{2}$ (argon as carrier gas, $100{ }^{\circ} \mathrm{C}, 150 \mathrm{kPa}$ ) and a polystyrene-divinylbenzene column to measure the $\mathrm{CO}_{2}$ and $\mathrm{CH}_{4}$ (helium as carrier gas, $45{ }^{\circ} \mathrm{C}, 150 \mathrm{kPa}$ ). Calibration was performed with pure gases and an $\mathrm{H}_{2-}$ $\mathrm{CH}_{4}-\mathrm{CO}_{2}$ mix (60:10:30\%). The mineral deposit observed on the cathode surface was analysed by Inductively Coupled Plasma Spectroscopy (Jobin Yvon Ultima ICP).

The acetate concentration was regularly measured with an enzymatic kit (Libios, K-ACETAK). When the concentration fell below a given minimum threshold (usually 5 to $10 \mathrm{mM}$ ), sodium acetate, in the form of a concentrated solution ( $4 \mathrm{M}$ ), was added to recover the initial concentration (usually $40 \mathrm{mM}$ ).

The compositions of the cathode deposits were determined by energy-dispersive-X-ray spectroscopy (EDX, SAEDX Oxford detector) with a scanning electron microscope (Leo 436 VP). The deposits were removed by scraping and the average values and standard deviations were based on four different samples, which gave similar spectra.

\section{Results and discussion}

\subsection{Ohmic drops}

The global internal resistance of the reactor was checked experimentally in abiotic conditions. The reactor was filled with the electrolyte, without inoculum, and current was imposed from 1 to 3.5 A, i.e. with current densities from 45 to $159 \mathrm{~A} \cdot \mathrm{m}^{-2}$ with respect to the cathode surface area. The cell voltage varied linearly with the current, which was evidence of ohmic behaviour in this range of current values. In such operating conditions, the slope of the curve gave the ohmic resistance of the reactor, which was $0.31 \Omega$.

The contribution of the electrolyte to the ohmic drop can be evaluated theoretically. In a coaxial reactor (Fig. 1) the resistance of the electrolyte is given by:

$R_{S}=\int_{r_{1}}^{r_{2}} \frac{\rho}{2 \pi r h} d r$

where $r_{1}(\mathrm{~m})$ is the cathode radius, $r_{2}(\mathrm{~m})$ is the anode radius, $h(\mathrm{~m})$ is the electrode height and $\rho(\Omega \cdot \mathrm{m})$ is the electrolyte resistivity. Here, the 


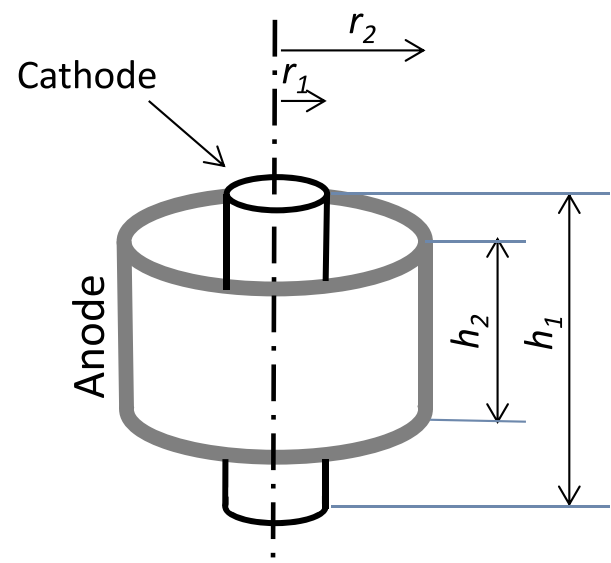

Fig. 1. Scheme of coaxial MEC. The length of the cathode exposed to the electrolyte is greater than the height of the bioanode.

height $\left(\mathrm{h}_{2}=0.20 \mathrm{~m}\right)$ of the anode, which was fully embedded in the electrolyte, was smaller than the length of the cathode exposed to the electrolyte $\left(h_{1}=0.35 \mathrm{~m}\right.$ ) (Fig. 1). Consequently, the height $h$ in the integral depends on the parameter $r$ as:

$h=h_{2}+\left(h_{1}-h_{2}\right) \frac{r_{2}-r}{r_{2}-r_{1}}$

where $h_{1}$ is the cathode height and $h_{2}$ is the anode height. Eq. (2) becomes:

$R_{S}=\frac{\rho}{2 \pi} \int_{r_{1}}^{r_{2}} \frac{1}{r(a r+b)} d r$

where $a$ and $b$ are two constants:

$a=-\frac{h_{1}-h_{2}}{r_{2}-r_{1}} \quad b=h_{2}+\frac{h_{1}-h_{2}}{r_{2}-r_{1}} r_{2}$

Eq. (4) can be solved to give:

$R_{S}=\frac{\rho}{2 \pi} \frac{1}{b} \ln \left(\frac{r_{2}}{a r_{2}+b} \frac{a r_{1}+b}{r_{1}}\right)$

For the MEC designed here, the values of the parameters $r_{1}=0.01 \mathrm{~m}, r_{2}=0.0635 \mathrm{~m}$ and $\rho=0.096 \Omega \cdot \mathrm{m}$ gave a resistance of the electrolyte of $0.10 \Omega$.

The difference between the theoretical value of the electrolyte resistance, of $0.10 \Omega$, and the total ohmic resistance, measured at $0.31 \Omega$, shows the importance of the resistances due to the electrical connections. These resistances particularly include the contact between the carbon felt and the titanium collector (Rousseau et al., 2015), welds and clamps. This points out that technical issues can become more important sources of power loss than the electrolyte resistance when a high conductivity electrolyte is used. These technical sources of power loss should obviously be tracked down and lowered as far as possible when the objective is to scale up to large-sized electrolysers with highly conductive electrolytes.

\subsection{MEC operation}

The MEC was inoculated with $5 \% \mathrm{v} / \mathrm{v}$ salt marsh sediment and run at $40{ }^{\circ} \mathrm{C}$ with the bioanode polarized at $0.1 \mathrm{~V} / \mathrm{SCE}$. After 2 days of initial time lag, the current density increased continuously to above $50 \mathrm{~A} \cdot \mathrm{m}^{-2}$ at day 11 , and then decreased although the acetate concentration was maintained between 10 and $50 \mathrm{mM}$ (Fig. 2). At day 14, addition of 3\% $\mathrm{v} / \mathrm{v}$ sediments led to a fast increase of current density, by around 10 $\mathrm{A} \cdot \mathrm{m}^{-2}$. It can be concluded that the initial amount of inoculum was not sufficient to ensure sustainable development of an electrochemically efficient biofilm. Unfortunately, the current increase was transient and the current fell again from day 15, while the acetate concentration was still around $30 \mathrm{mM}$. The addition of inoculum, which required opening the reactor, changed the gaseous head space of the reactor to air. We suspected that the slow diffusion of oxygen to the bioanode was the reason for the current density fall observed after day 15. Acetate addition was stopped from day 15 in order let the reactor recover regular operating conditions, which proved to be successful at day 20 .

Acetate concentration was allowed to fall to zero to start a new phase on day 20. At day 20 (phase II) acetate was added and the current density increased to above $80 \mathrm{~A} \cdot \mathrm{m}^{-2}$ in $<3$ days. The successive additions of acetate ranging from 40 to $55 \mathrm{mM}$ (Fig. 2) caused the current density to increase, reaching $90 \mathrm{~A} \cdot \mathrm{m}^{-2}$ at day 25 .

Acetate concentration was again allowed to fall and phase III was then performed by adding acetate at day 28. Current density again increased continuously, but at a lower rate than during phase II. Increasing the concentration of acetate to above $50 \mathrm{mM}$ did not accelerate the recovery phase. When the current density reached around $80 \mathrm{~A} \cdot \mathrm{m}^{-2}$, the acetate level was allowed to fall again but the MEC was not left in starvation conditions for as long a time as previously. Phase IV started with faster current recovery (day 41). Phase V was started at day 45 by emptying $3 \mathrm{~L}$ of solution (of the $5.25 \mathrm{~L}$ ), which was replaced by fresh electrolyte. The production of current was not disturbed by this drastic operation. Finally, increasing the successive acetate additions to above $65 \mathrm{mM}$ and up to $74 \mathrm{mM}$ had an inhibiting effect on current production.

The decrease in current density observed for acetate concentrations below around $10 \mathrm{mM}$ and the inhibiting effect observed for high concentrations indicated an optimal range of acetate concentration of 10 to $60 \mathrm{mM}$. This behaviour is consistent with general observations showing that the current provided by microbial anodes fed with acetate varies with the substrate concentration according to a Michaelis-Menten type law:

$j=j_{\max } \frac{[\text { acetate }]}{K_{S}+[\text { acetate }]}$

where $K_{S}$ is an affinity constant of the order of a few $\mathrm{mM}$ (Marcus et al., 2007; Pocaznoi et al., 2012b). Substrate inhibition is generally found to occur for concentrations above about $50 \mathrm{mM}$ (Pocaznoi et al., 2012b).

The successive five phases imposed on the MEC revealed good robustness of the process with respect to acetate depletion. Actually, an over-long period of starvation, as between phases II and III, for instance, should be avoided because the rate of current restoration was then slower. Nevertheless, the maximum current density was reached again, and the MEC did not show any further disturbance.

The five successive phases of the MEC operation gave anode Faradaic yields that were related to acetate consumption slightly higher than $100 \%$ (Table 1). The values higher than $100 \%$ indicate that more electrons were released into the circuit than the amount that could result from the substrate oxidation. This phenomenon reveals hydrogen cycling to the bioanode (Escapa et al., 2015; Gil-Carrera et al., 2013c; Lee et al., 2009; Parameswaran et al., 2009; Rousseau et al., 2020). Actually, a point not even observed in the context of MECs yet: similar oxidation at the anode may occur with methane (Rousseau et al., 2020). Here, the slight increase of the Faradaic yields from the first to the fifth phase may indicate the involvement of microbial catalysis in such a reoxidation cycle. The bioanode adapted to the presence of hydrogen or methane and thus became more and more efficient at oxidizing them.

The reactor was run again with a clean anode and cathode, with an inoculum ratio of $10 \% \mathrm{v} / \mathrm{v}$ and with the acetate concentration maintained around $40 \mathrm{mM}$ by daily measurement and addition. After 2 days of initial time lag, it took 25 days for the current density to reach 70 A. $\mathrm{m}^{-2}$ (Fig. 3). After a few days of acetate depletion (days 29 and 30), the current density increased again and reached the maximum of 85 A. $\mathrm{m}^{-2}$ at day 33. The current then started to decrease from day 37 , although the acetate concentration was maintained around $40 \mathrm{mM}$. At day 46, the reactor was emptied, except for the sediment deposited at 

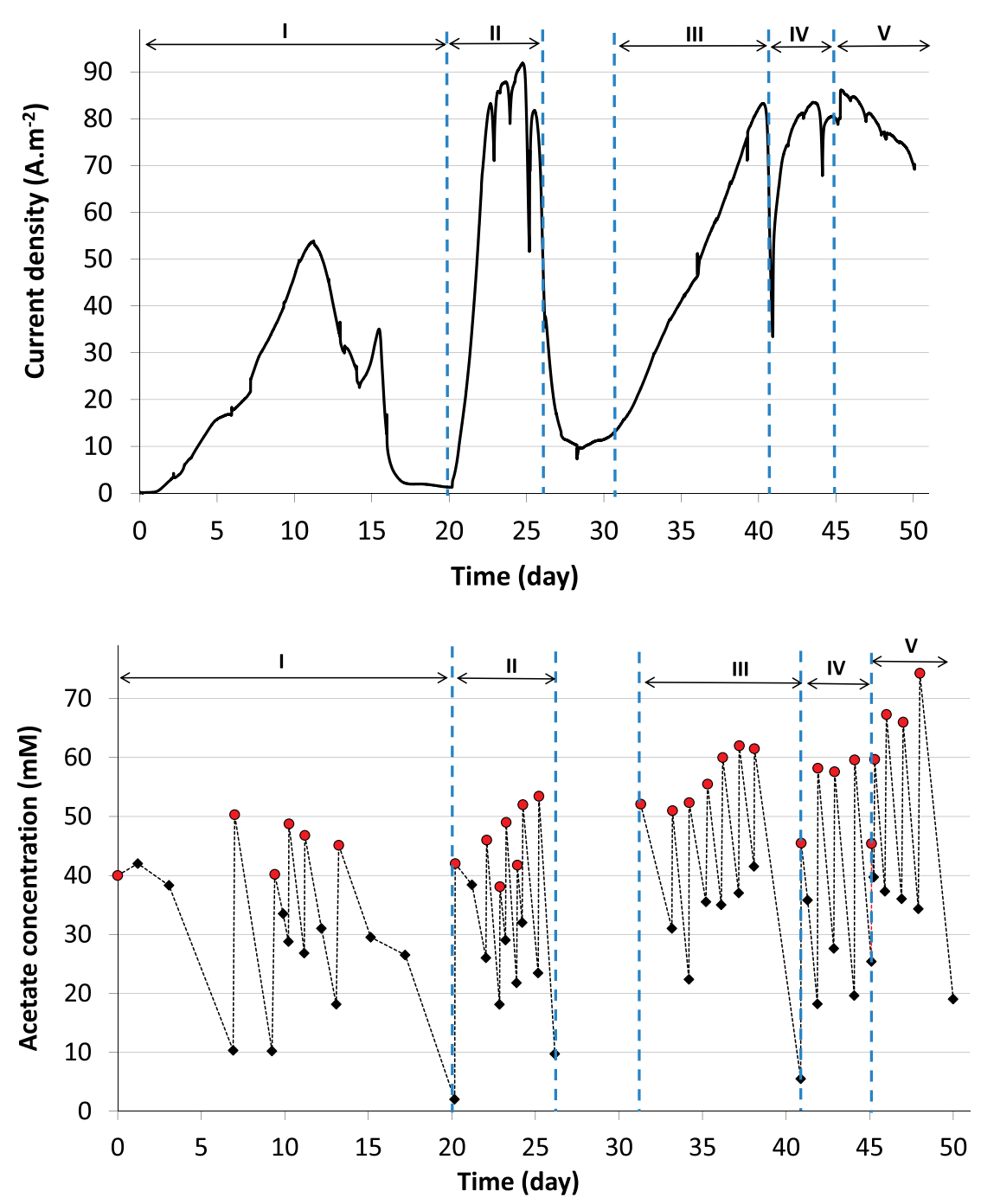

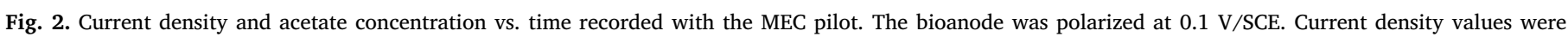

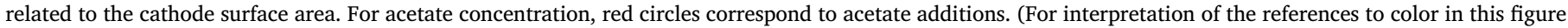
legend, the reader is referred to the web version of this article.)

Table 1

Anode Faradaic yields related to acetate consumption. Faradaic yields were calculated for each of the five phases reported in Fig. 2.

\begin{tabular}{lrrrrrrr}
\hline Phase & I & II & III & IV & \multicolumn{2}{c}{ V } \\
\hline $\begin{array}{c}\text { Total amount of acetate oxidized during the } \\
\text { phase (mole) }\end{array}$ & 0.96 & 0.88 & 1.01 & 0.70 & 0.79 \\
\begin{tabular}{l} 
Faradaic yield (\%) \\
\hline
\end{tabular} & 103 & 107 & 116 & 113 & 123 \\
\hline
\end{tabular}

the bottom, and refilled with fresh electrolyte. The current density immediately increased and recovered the value of $70 \mathrm{~A} \cdot \mathrm{m}^{-2}$ found at day 53.

The second run confirmed the possibility of maintaining the current density above $50 \mathrm{~A} \cdot \mathrm{m}^{-2}$ for weeks. It also confirmed that the initial phase of the bioanode formation was poorly mastered but, finally, the reactor always succeeded in producing similar, high current densities. The uncontrolled current decrease from day 37 was fully repaired by replacing the whole electrolyte by fresh medium at day 46 , which suggests that the current decrease may have been due to the depletion of some micro-nutriments contained in the Starkey medium.

The gas flow rate $\left(Q_{g a s}\right)$ measured for different values of the current $(0.5,1.0,1.5$ and $2.0 \mathrm{~A}$ at days $7,10,22$ and 24 of the first run) showed a linear correlation with the current density:
$Q_{\text {gas }}=11.6 j-59.2$

where $Q_{\text {gas }}\left(\mathrm{L} \cdot \mathrm{d}^{-1} \cdot \mathrm{m}^{-2}\right)$ is the gas flow rate related to the cathode surface area and $j\left(\mathrm{~A} \cdot \mathrm{m}^{-2}\right)$ the current density. This correlation was valid $\left(R^{2}=0.99\right)$ for current densities above around $20 \mathrm{~A} \cdot \mathrm{m}^{-2}$. The composition of the gas was measured at various times corresponding to different current densities. The outlet gas was mainly composed of hydrogen (66 to $71 \%$ ) and carbon dioxide (16 to $29 \%$ ). A significant percentage of methane was always present (5 to $13 \%$ ). The composition at the maximum current density of $90 \mathrm{~A} . \mathrm{m}^{-2}$, at day 23, was 66, 29 and $5 \%$ in $\mathrm{H}_{2}, \mathrm{CO}_{2}$ and $\mathrm{CH}_{4}$, respectively.

At the end of MEC operations, the cathode was seen to be covered by a compact, strongly adherent layer composed of brown and white deposits. EDX analysis of the white deposits revealed a high oxygen content (54.4 \pm 0.9 atom\%) and carbon (22.1 \pm 1.0 atom\%), which strongly suggests the presence of carbonate as the main anion. The other major components of the deposits were magnesium (11.1 \pm 0.2 and $11.7 \pm 0.5$ atom $\%$ in the white and brown deposits, respectively), phosphorous (9.2 \pm 0.7 and $10.5 \pm 0.3$ atom\%) and calcium $(3.1 \pm 0.9$ atom $\%$ in the brown deposit only). The phosphorous came from the Starkey medium and magnesium and calcium from the sediment. The $\mathrm{OH}^{-}$ions produced at the cathode provoked the alkalinization of the interface, which made carbonates and phosphates of magnesium and calcium precipitate onto the cathode surface. 


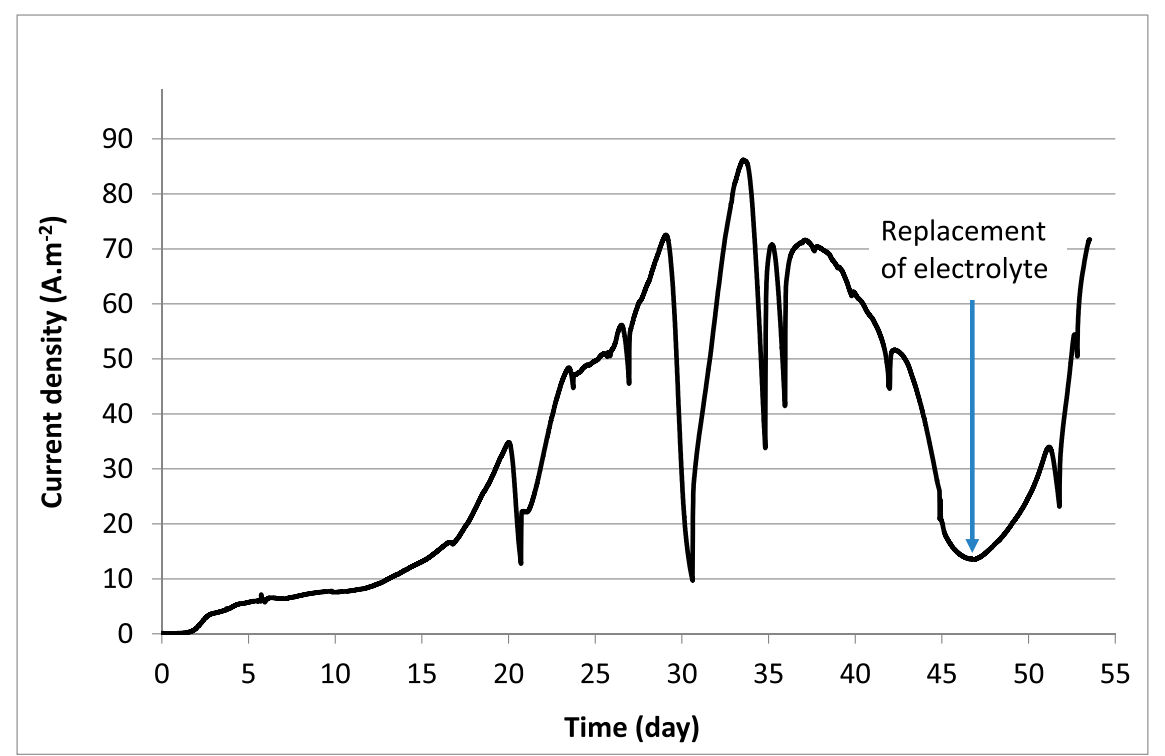

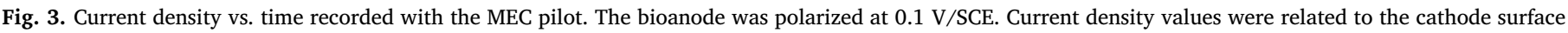
area. Acetate concentration was maintained around $40 \mathrm{mM}$ by daily adjustments except on days 20,29 and 30 .

In conclusion, the formation of the salt marsh bioanode is still poorly mastered and the periods of time needed to reach high electroactive performance can be fairly different. Here, 10 to 25 days were necessary to reach $50 \mathrm{~A} \cdot \mathrm{m}^{-2}$. A high inoculation ratio of $10 \% \mathrm{v} / \mathrm{v}$ with salt marsh seemed necessary, while the significant concentration of magnesium and calcium ions it provided may have favoured fouling of the cathode by precipitation. Such chemical fouling is obviously detrimental to the cathode performance. Nevertheless the cathode surface was perfectly cleaned with $\mathrm{HCl} 1 \mathrm{M}$, which quickly dissolved the whole deposit.

The MEC showed fair robustness. It accepted several days of acetate starvation, after which it was able to slowly recover its maximum current density. When acetate depletion did not last more than one day, the current density recovered very quickly after addition. The MEC accepted partial $(3 \mathrm{~L})$ or total replacement of the solution. This operation was required after a period of high current production, certainly because of the depletion of some micro-nutriment(s). Current density of up to $90 \mathrm{~A} \cdot \mathrm{m}^{-2}$ was reached and values above $50 \mathrm{~A} \cdot \mathrm{m}^{-2}$ were sustained for weeks. It should be noted that the current density values were expressed with respect to the surface area of the cathode, which had a smooth stainless steel surface. These current density values were consequently obtained without any enhancement due to porosity or threedimensional effects.

\subsection{Energy efficiency}

The MEC was operated under constant applied potential at the bioanode. As explained in the introduction, this operating mode is not appropriate for industrial implementation but was used here to keep the bioanode at the optimal condition. When the MECs produced 50 to 90 $\mathrm{A} \cdot \mathrm{m}^{-2}$ the voltage ranged from 1.3 to $1.6 \mathrm{~V}$. These values are far from the equilibrium cell voltage of $0.123 \mathrm{~V}$ in standard conditions for MECs fed with acetate.

The current-potential curve of each electrode was recorded by varying the potential applied at the bioanode and measuring the potential of the cathode (Fig. 4). They were recorded at the end of the first MEC run. These curves showed significant overpotential on both the bioanode and the cathode. For instance, with the potential of the bioanode at $0.1 \mathrm{~V} / \mathrm{SCE}$, the MEC produced $62 \mathrm{~A} \cdot \mathrm{m}^{-2}$ under $1.4 \mathrm{~V}$ voltage. In this operating condition, the overpotential of both the bioanode and the cathode was around $0.64 \mathrm{~V}$. Improving the electrode kinetics

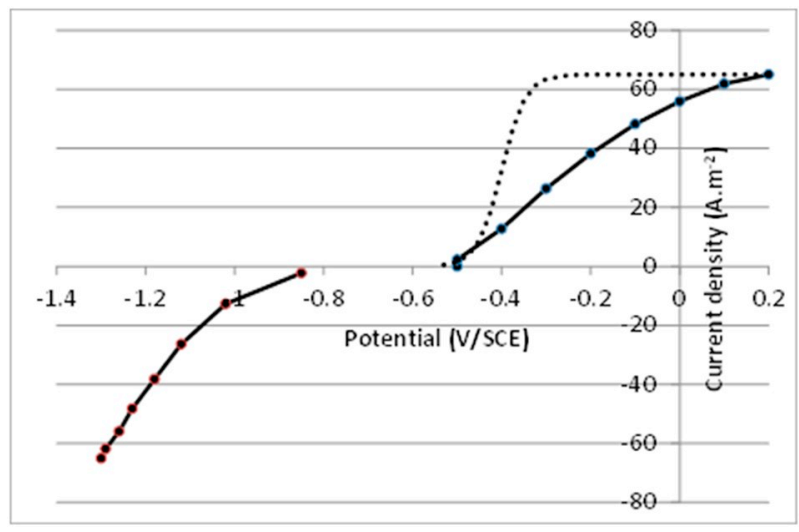

Fig. 4. Current density vs. potential recorded in the MEC pilot by applying different potentials at the bioanode. Record was performed at the end of the first run, day 51. The dotted line is the theoretical Nernst-Michaelis-Menten kinetics plotted with $\mathrm{J}_{\max }=65 \mathrm{~A} \cdot \mathrm{m}^{-2}$ and $\mathrm{E}_{1 / 2}=-0.40 \mathrm{~V} / \mathrm{SCE}$ (Torres et al., 2008; Rimboud et al., 2015).

would consequently be a worthwhile purpose of further research for both the bioanode and the cathode.

For comparison, theoretical bioanode kinetics was plotted with a Nernst-Michaelis-Menten equation (Torres et al., 2008; Rimboud et al., 2015). This equation represents the best kinetics that could be reached by assuming that electron transfer at the electrode surface is fast enough to ensure the Nernst equilibrium of the redox species. It showed the large range of improvement that could be gained by improving the bioanode kinetics. Actually, multi-species bioanodes have already proved to be able to generate very high current density with kinetics close to Nernst-Michaelis-Menten type but in solutions of low salinity (Chen et al., 2012; Pocaznoi et al., 2012a; Ketep et al., 2014; Baudler et al., 2015). The bioanodes used here had the great advantage of working in a highly saline medium but their kinetics remain to be improved. A gain close to $400 \mathrm{mV}$ might be reached at a current density of the order of $60 \mathrm{~A} \cdot \mathrm{m}^{-2}$ if we could accelerate the electron transfers. This shows the great interest of working on the basic understanding of the electron transfer mechanism of halotolerant bioanodes (Grattieri et al., 2017; Grattieri and Minteer, 2018) and the practical ways to apply them (Alkotaini et al., 2018). 
The energy yield $\left(\gamma_{G}\right)$ of an electrolyser whose function is to produce pure hydrogen is expressed as the ratio of the energy that could be recovered from the hydrogen produced to the electric energy consumed to generate it (Wendt and Kreysa, 1999):

$\gamma_{\mathrm{G}}=\frac{N_{H 2} \quad \Delta G_{c, H_{2}}^{0}}{U \quad J}$

where $N_{H 2}\left(\mathrm{~mol} \cdot \mathrm{s}^{-1} \cdot \mathrm{m}^{-2}\right)$ is the molar flux of hydrogen per unit cathode surface area, $U(\mathrm{~V})$ is the cell voltage, $\mathrm{J}\left(\mathrm{A} \cdot \mathrm{m}^{-2}\right)$ is the current density and $\Delta G_{c, H 2}^{0}\left(\mathrm{~J} \cdot \mathrm{mol}^{-1}\right)$ is the absolute value of the standard Gibbs free energy change for hydrogen combustion $\left(237.1 \mathrm{~kJ} \cdot \mathrm{mol}^{-1}\right)$.

If hydrogen is intended to be burned, the thermal energy yield $\left(\gamma_{H}\right)$ is assessed by using the standard enthalpy change of hydrogen combustion. Moreover, in this case, it may be useful to produce a mix of hydrogen and methane, for instance to be introduced into the gas distribution network. Both methane and hydrogen are used for their heat of combustion. The thermal energy yield $\gamma_{\mathrm{H}}$ is consequently calculated by taking the enthalpies of combustion of both hydrogen and methane into account:

$\gamma_{\mathrm{H}}=\frac{N_{H_{2}} \Delta H_{c, H_{2}}^{0}+N_{C H 4} \Delta H_{c, N H_{4}}^{0}}{U} J$

where $\Delta H_{c, H 2}^{0}$ is the absolute value of the standard enthalpy change of hydrogen combustion $\left(286 \mathrm{~kJ} \cdot \mathrm{mol}^{-1}\right.$ ), $\Delta H_{c, C H 4}^{0}$ is the absolute value of the standard enthalpy change of methane combustion $\left(891 \mathrm{~kJ} \cdot \mathrm{mol}^{-1}\right)$, $N_{H 2}$ and $N_{C H 4}\left(\mathrm{~mol} \cdot \mathrm{s}^{-1} \cdot \mathrm{m}^{-2}\right)$ are the molar flux of hydrogen and methane per unit cathode surface area.

The energy yield, $\gamma_{\mathrm{G}}$, and the thermal energy yield, $\gamma_{\mathrm{H}}$, were evaluated (Table 2) by using the experimental measurement of the whole gas flow rate (Eq. (8)) with a composition of $66 \% \mathrm{H}_{2}, 29 \% \mathrm{CO}_{2}$ and $5 \%$ $\mathrm{CH}_{4}$, which was representative of the gas produced at high current density (phase II).

The $\gamma_{G}$ values reported for MEC pilots so far range from 0 (complete transformation to $\mathrm{CH}_{4}$ ) to 1.2 (Gil-Carrera et al., 2013c) and 1.25 (SanMartín et al., 2019), with most values around 0.5 to 0.7 (CarmonaMartinez et al., 2015; Gil-Carrera et al., 2013a; Heidrich et al., 2013; Luo et al., 2017). Some very high values, up to 7.5, are beyond the scope of MECs because the majority of hydrogen was produced by sugar fermentation in this case (Cusick et al., 2011). Apart from this value, the highest values obtained in MEC pilots, of 1.25 (San-Martín et al., 2019), 1.2 (Gil-Carrera et al., 2013c), 1.03 (Baeza et al., 2017), and 0.69 (Heidrich et al., 2013; Luo et al., 2017), were obtained for current densities significantly lower than those sustained here $\left(<2 \mathrm{~A} \cdot \mathrm{m}^{-2}\right)$. Here, at current density of $20 \mathrm{~A} \cdot \mathrm{m}^{-2}$, hydrogen was produced at a significant flow rate $\left(114 \mathrm{~L} \cdot \mathrm{d}^{-1} \cdot \mathrm{m}^{-2}\right)$, with an energy yield $\gamma_{\mathrm{G}}=0.85$. The energy yield remained above 0.5 at $60 \mathrm{~A} \cdot \mathrm{m}^{-2}$. Here, the cathode current density was considerably increased with respect to those in previous MEC pilots, while keeping energy yield at the same level. These results represent significant progress with respect to the experimental state of the art for MEC pilots.

The value of the thermal energy yield, 1.26, at the current density of $20 \mathrm{~A} \cdot \mathrm{m}^{-2}$, is encouraging because it is higher than the theoretical

Table 2

Experimental energy and thermal energy yields. $Q_{H 2}$ and $Q_{C H 4}$ were calculated from the experimental correlation (8) with a gas composition of $66 \% \mathrm{H}_{2}, 29 \%$ $\mathrm{CO}_{2}$ and $5 \% \mathrm{CH}_{4}$. Molar fluxes were calculated by dividing the volume flow rates, Q, by the molar volume of perfect gas $(25.69 \mathrm{~L}$ at $313.15 \mathrm{~K})$. U was extracted from Fig. 4, except for $90 \mathrm{~A} \cdot \mathrm{m}^{-2}$, which corresponded to day 24 of the first run.

\begin{tabular}{llclll}
\hline$J\left(\mathrm{~A} \cdot \mathrm{m}^{-2}\right)$ & $Q_{H 2}\left(\mathrm{~L} \cdot \mathrm{d}^{-1} \cdot \mathrm{m}^{-2}\right)$ & $Q_{C H 4}\left(\mathrm{~L} \cdot \mathrm{d}^{-1} \cdot \mathrm{m}^{-2}\right)$ & $U(\mathrm{~V})$ & $\gamma_{\mathrm{G}}(-)$ & $\gamma_{\mathrm{H}}(-)$ \\
\hline 20 & 114.0 & 8.6 & 0.72 & 0.85 & 1.26 \\
40 & 267.2 & 20.2 & 1.01 & 0.71 & 1.05 \\
60 & 420.3 & 31.8 & 1.34 & 0.56 & 0.83 \\
90 & 650.0 & 49.2 & 1.6 & 0.48 & 0.72 \\
\hline
\end{tabular}

maximum limit of a conventional water electrolysis cell, equal to 1.21 . This value confirmed the interest of MECs for producing a mix of methane and hydrogen (Geppert et al., 2016; Luo et al., 2017). Nevertheless, much room remains for improvement if we are to tend to the theoretical limit value of around 12 (Rousseau et al., 2020).

Two major causes explain the energy loss. On the one hand, when it operated in the range from 20 to $90 \mathrm{~A} \cdot \mathrm{m}^{-2}$, the MEC had a cell voltage of 0.72 to $1.6 \mathrm{~V}$, far from the formal equilibrium cell voltage $(0.123 \mathrm{~V})$. When the current density increased, the energy and thermal energy yields decreased significantly, as could be anticipated by glancing at the large overpotentials shown by the current-potential curves (Fig. 4). To produce significant current density, the MEC pilot operated far from the thermodynamic threshold. In this objective, improving the kinetics of both the bioanode and the cathode is an essential challenge. There is great scope for progress in this regard.

\section{Mass balance modelling}

The theoretical production of the MEC was calculated via the electron balance sheet associated with a simple reactional scheme. Acetate is oxidized at the bioanode:

$\mathrm{CH}_{3} \mathrm{COO}^{-}+2 \mathrm{H}_{2} \mathrm{O} \rightarrow 2 \mathrm{CO}_{2}+7 \mathrm{H}^{+}+8 \mathrm{e}^{-}$

Hydrogen is produced at the cathode:

$2 \mathrm{H}_{2} \mathrm{O}+2 \mathrm{e}^{-} \rightarrow \mathrm{H}_{2}+2 \mathrm{OH}^{-}$

Hydrogen can react with $\mathrm{CO}_{2}$ in the bulk to give methane:

$4 \mathrm{H}_{2}+\mathrm{CO}_{2} \rightarrow \mathrm{CH}_{4}+2 \mathrm{H}_{2} \mathrm{O}$

Hydrogen can be re-oxidized on the bioanode:

$\mathrm{H}_{2} \rightarrow 2 \mathrm{H}^{+}+2 \mathrm{e}^{-}$ face.

$\mathrm{CO}_{2}$ can be lost by precipitation to carbonate on the cathode sur-

The balance sheet was drawn up on the basis on $1 \mathrm{~mol}$ of electrons passing through the electrical circuit. Three unknown parameters are introduced:

- $n_{\mathrm{CH} 4}$ : the number of moles of $\mathrm{CH}_{4}$ produced by reaction of $\mathrm{CO}_{2}$ with $\mathrm{H}_{2}$ (Reaction (12)),

- $n_{\mathrm{H} 2}$ : the number of moles of $\mathrm{H}_{2}$ lost by re-oxidation at the anode (Reaction (13)),

- $n_{\text {carbo }}$ : the number of moles of $\mathrm{CO}_{2}$ lost by precipitation to carbonate at the cathode.

When 1 mol of electrons passes through the circuit:

- $\left(1-2 n_{H 2}\right)$ mole of electrons is produced by the oxidation of acetate,

- $\left(1-2 n_{\mathrm{H} 2}\right) 0.25 \mathrm{~mol}$ of $\mathrm{CO}_{2}$ is produced at the bioanode (Reaction (1)), $n_{C H 4}$ mole of this $\mathrm{CO}_{2}$ is transformed to $\mathrm{CH}_{4}$ (Reaction (12)), and $n_{\text {carbo }}$ mole is lost at the cathode, which results in $\left(\left(1-2 n_{\mathrm{H} 2}\right)\right.$ $0.25-n_{\mathrm{CH} 4}-n_{\text {carbo }}$ ) mole of $\mathrm{CO}_{2}$ coming out of the MEC,

- $0.5 \mathrm{~mol}$ of $\mathrm{H}_{2}$ is produced at the cathode (Reaction (11)), $4 n_{\mathrm{CH}_{4}}$ mole of this $\mathrm{H}_{2}$ is converted to $\mathrm{CH}_{4}$, (Reaction (12)) and $n_{H 2}$ mole is lost by oxidation at the bioanode (Reaction (13)), which results in $\left(0.5-4 n_{\mathrm{CH} 4}-n_{\mathrm{H} 2}\right)$ mole of $\mathrm{H}_{2}$ coming out of the MEC,

- $n_{\mathrm{CH} 4}$ mole of $\mathrm{CH}_{4}$ is produced by the combination of $\mathrm{H}_{2}$ with $\mathrm{CO}_{2}$ (Reaction (12)).

The molar flux of each compound produced by a current density equal to $J$ is obtained by multiplying the numbers of moles resulting from the mass balance sheet detailed above (Table 3, first column) by $J /$ $F$. Finally, the total molar flux of gas that comes out of the MEC is given by the sum of all the fluxes (Table 3 , last line). The gas composition in percentages is obtained by dividing the molar flux of each compound by 
Table 3

Theoretical molar fluxes and gas composition produced by a MEC. $n_{\mathrm{CH} 4}$ is the number of mole of $\mathrm{CH}_{4}$ produced per mole of electrons passing through the circuit, and $n_{\mathrm{H} 2}$ is the number of mole of $\mathrm{H}_{2}$ lost by re-oxidation at the bioanode per mole of electrons passing through the circuit.

\begin{tabular}{lll}
\hline & $\begin{array}{l}\text { Gas molar flux } \\
\left(\mathrm{mol} \cdot \mathrm{s}^{-1} \cdot \mathrm{m}^{-2}\right)\end{array}$ & $\begin{array}{l}\text { Gas composition } \\
(\%)\end{array}$ \\
\hline $\mathrm{CO}_{2}$ & $\frac{J}{F}\left(\left(1-2 n_{H 2}\right) 0.25-n_{\mathrm{CH} 4}-n_{\text {carbo }}\right)$ & $\frac{\left(1-2 n_{H 2}\right) 0.25-n_{C H 4}-n_{\text {carbo }}}{0.75-1.5 n_{H 2}-4 n_{C H}-n_{\text {carbo }}} 100$ \\
$\mathrm{H}_{2}$ & $\frac{J}{F}\left(0.5-4 n_{\mathrm{CH} 4}-\mathrm{n}_{\mathrm{H} 2}\right)$ & $\frac{0.5-4 n_{C H 4}-n_{H 2}}{0.75-1.5 n_{H 2}-4 n_{C H}-n_{\text {carbo }}} 100$ \\
$\mathrm{CH}_{4}$ & $\frac{J}{F} n_{\mathrm{CH} 4}$ & $\frac{n_{C H 4}}{0.75-1.5 n_{H 2}-4 n_{C H 4}-n_{\text {carbo }}} 100$ \\
Total & $\frac{J}{F}\left(0.75-1.5 n_{H 2}-4 n_{\mathrm{CH} 4}-n_{\text {carbo }}\right)$ & 100 \\
\hline
\end{tabular}

the total gas molar flux (Table 3, second column).

The total gas molar flux, equal to $\frac{J}{F}(0.75$ $\left.1.5 n_{\mathrm{H} 2}-4 n_{\mathrm{CH} 4}-n_{\text {carbo }}\right)\left(\mathrm{mol} \cdot \mathrm{s}^{-1} \cdot \mathrm{m}^{-2}\right)$ gives the overall gas flow rate related to the cathode surface area $Q_{\text {gas model }}\left(\mathrm{L} \cdot \mathrm{d}^{-1} \cdot \mathrm{m}^{-2}\right)$ as:

$Q_{\text {gas model }}=\frac{J}{F}\left(0.75-1.5 n_{H 2}-4 n_{C H 4}\right) V_{m} \times 3600 \times 24$

where $V_{m}$ is the molar volume of a perfect gas $\left(V_{m}=24.0 \mathrm{~L}\right.$ at $20{ }^{\circ} \mathrm{C}$, temperature of the measurement).

According to the mass balance sheet above, the anode Faradaic yield related to acetate oxidation is:

$\Phi_{\text {acetate }}=\frac{1}{1-2 n_{H 2}} 100$

The theoretical mass balance was used in order to match the experimental data recorded when the highest value of the current density was reached ( $J=90 \mathrm{~A} \cdot \mathrm{m}^{-2}$ ) at day 23, phase II of the first run (Fig. 2). The overall gas flow rate related to the cathode surface area was $985 \mathrm{~L} \cdot \mathrm{d}^{-1} \cdot \mathrm{m}^{-2}$, the Faradaic yield related to acetate was $107 \%$ and the gas composition 66,29 and $5 \%$ of $\mathrm{H}_{2}, \mathrm{CO}_{2}$ and $\mathrm{CH}_{4}$ respectively (Table 4).

The three unknown parameters $\left(n_{\mathrm{CH} 4}, n_{\mathrm{H} 2}, n_{\text {carbo }}\right)$ had to be numerically fitted in order to check the capacity of the model to match the experimental data. Firstly, the parameter $n_{H 2}$ was set to 0.033 so that Faradaic yield was equal to $107 \%$ (Eq. (15)). This value was kept constant thereafter. Then, the parameter $n_{\mathrm{CH} 4}$ was set at 0.029 so that the $\mathrm{CH}_{4}$ ratio was equal to $5 \%$. In this case (Case 1 in Table 4) $\mathrm{H}_{2}$ and $\mathrm{CO}_{2}$ ratios were 60 and $35 \%$, respectively. These values did not fully match the experimental data: the $\mathrm{H}_{2}$ ratio was lower and the $\mathrm{CO}_{2}$ ratio higher than the measured values. Case 2 was consequently calculated by adjusting the $n_{\mathrm{CH} 4}$ and $n_{\text {carbo }}$ parameters simultaneously. The values $n_{\mathrm{CH} 4}=0.027$ and $n_{\text {carbo }}=0.049$ led to a perfect match of the gas composition. This result points out that the deposit of carbonate on the cathode impacts the overall mass balance.

The overall gas flow rate (Eq. (14)) was slightly higher than the experimental value, but by $<7 \%$. This small increase may be explained

\section{Table 4}

Experimental and theoretical values of the gas composition, the overall flow rate and the anode Faradaic yield. Experimental data were recorded at $J=90$ $\mathrm{A} \cdot \mathrm{m}^{-2}$. The mass balance model was run for two cases: Case 1 did not take carbonate deposit on the cathode into account $\left(n_{\mathrm{H} 2}=0.033, n_{\mathrm{CH} 4}=0.029\right.$ and $\left.n_{\text {carbo }}=0\right)$; Case 2 included carbonate deposit $\left(n_{H 2}=0.033, n_{C H 4}=0.027\right.$ and $n_{\text {carbo }}=0.049$ ).

\begin{tabular}{lrrr}
\hline & Experimental values & Case 1 & Case 2 \\
\hline $\mathrm{CO}_{2}(\%)$ & 29 & 35 & 29 \\
$\mathrm{H}_{2}(\%)$ & 66 & 60 & 66 \\
$\mathrm{CH}_{4}(\%)$ & 5 & 5 & 5 \\
$Q_{\text {gas model }}\left(\mathrm{L} \cdot \mathrm{d}^{-1} \cdot \mathrm{m}^{-2}\right)$ & 985 & 1131 & 1051 \\
$\left.\Phi_{\text {acetate }} \%\right)$ & 107 & 107 & 107 \\
\hline
\end{tabular}

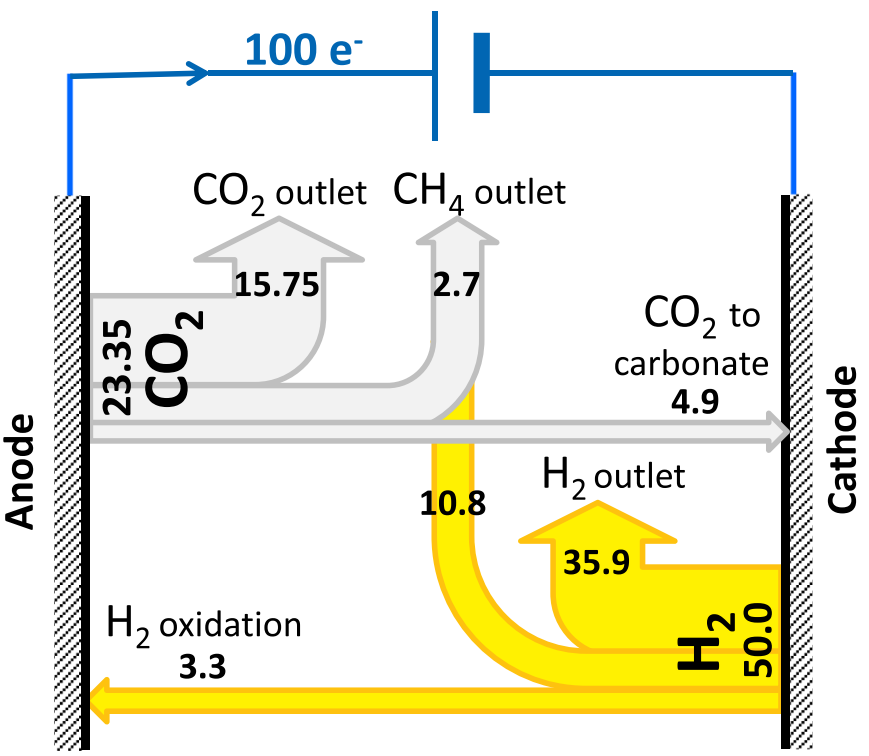

Fig. 5. Gas balance sheet for the MEC operating at $90 \mathrm{~A} \cdot \mathrm{m}^{-2}$. Balance is presented on the basis of $100 \mathrm{~mol}$ of electrons passing through the electrical circuit. The figures in the scheme give the number of moles of each compound in the different fluxes given by the model with $n_{H 2}=0.033, n_{C H 4}=0.027$ and $n_{\text {carbo }}=0.049$.

by some leaks, which are difficult to identify technically with the rather low gas production rates given by the MEC.

The mass balance model, which includes the deposition of carbonates, matches the experimental data. It therefore provides a relevant description of the gas flows within the MEC. On the basis of $1 \mathrm{~mol}$ of electrons passing through the electrical circuit, the model shows that $0.5 \mathrm{~mol}$ of hydrogen was produced at the cathode, of which $0.108 \mathrm{~mol}$ (22\%) was consumed to form $\mathrm{CH}_{4}$ and 0.033 mol (6.6\%) was oxidized at the cathode (Fig. 5).

Concerning $\mathrm{CO}_{2}$, $\left(1-2 n_{\mathrm{H} 2}\right) 0.25=0.2335 \mathrm{~mol}$ of $\mathrm{CO}_{2}$ was produced at the anode, of which $0.027 \mathrm{~mol}(12 \%)$ was converted to $\mathrm{CH}_{4}$, and $0.049 \mathrm{~mol}(21 \%)$ was lost to the cathode deposit. It is well known that cathode deposit is a major issue in MECs because it masks the cathode surface and decreases the hydrogen evolution rate (Sugnaux et al., 2017). Nevertheless, the numerical model pointed out the significant impact of carbonate deposit on the overall mass balance, to an extent that we had not anticipated before. Actually, this high impact may have been linked to the high current density ensured here by the cathode, which provoked severe local alkalinization of the cathode neighbourhood.

This effect might be seen as virtuous as it tends to decrease the proportion of $\mathrm{CO}_{2}$ in the gas outlet. In contrast, it would be a disadvantage if the objective was to produce $\mathrm{CH}_{4}$. Nevertheless, in any case, carbonate precipitation is detrimental to the cathode performance and would impose periodic cleaning of the cathode surface.

Carbonate deposition also induces the extraction of cations such as $\mathrm{Mg}^{2+}$ and $\mathrm{Ca}^{2+}$ from the medium, which may have a detrimental impact on the electroactive biofilm. For instance, the uncontrolled current decrease observed from day 37 in the second run, which was repaired by replacing the electrolyte by fresh medium at day 46 , may have been due to such depletion of mineral compounds. This hypothesis, which was suggested here by the numerical model, should be checked by experimental measurements in the future. When high current density is sustained at the cathode, the strong local alkalinization may become a major issue to be considered. The key importance of cathode alkalinisation has already been observed in terms of overpotential (Ruiz et al., 2016), it was shown to be strengthened here because of carbonate deposit.

The highly saline medium used here was a key to success by 
minimizing the ohmic drop due to the electrolyte. In counterpart, such saline media are detrimental to the mitigation of the $\mathrm{pH}$ gradients by the buffering species (Nam and Logan, 2012; Oliot et al., 2016). Furthermore, the buffer capacity of the Starkey medium used here was very low. Considering the importance of the impact of cathode alkalinisation, it would be advisable to increase the buffering capacity of the electrolyte as a priority way for future progress (Ruiz et al., 2015).

\section{Conclusions}

A significant step forward has been made here by making a cathode work at $90 \mathrm{~A} \cdot \mathrm{m}^{-2}$ in a MEC $6 \mathrm{~L}$ in volume, and by maintaining the current density above $50 \mathrm{~A} \cdot \mathrm{m}^{-2}$ for several weeks. Only one order of magnitude remains to be gained to bring the technology up to the level of low-cost commercial electrolysers performing water electrolysis. Furthermore, analysis of the results described here show that there is still much room for improvement, particularly by mitigating $\mathrm{pH}$ gradients in MECs and by working to master the formation phase and to improve the kinetics of halo-tolerant microbial anodes.

Declaration of competing interest

The authors declare that they have no known competing financial interests or personal relationships that could have appeared to influence the work reported in this paper.

\section{CRediT authorship contribution statement}

Raphaël Rousseau: Conceptualization, Investigation, Writing original draft. Stéphanie F. Ketep: Investigation. Luc Etcheverry: Methodology. Marie-Line Délia: Conceptualization, Validation, Writing - original draft, Supervision, Project administration. Alain Bergel: Conceptualization, Validation, Writing - original draft, Writing - review \& editing, Supervision, Funding acquisition.

\section{Acknowledgements}

This work was part of the "Défi H12" project financially supported by the "Bioénergies" programme of the French "Agence Nationale de la Recherche" (ANR-09-BioE-010 DéfiH12).

\section{References}

Alkotaini, B., Tinucci, S.L., Robertson, S.J., Hasan, K., Minteer, S.D., Grattieri, M., 2018. Alginate-encapsulated bacteria for the treatment of hypersaline solutions in microbial fuel cells. ChemBioChem 19, 1162-1169. https://doi.org/10.1002/cbic.201800142. Baeza, J.A., Martínez-Miró, À., Guerrero, J., Ruiz, Y., Guisasola, A., 2017. Bioelectrochemical hydrogen production from urban wastewater on a pilot scale. J. Power Sources 356, 500-509. https://doi.org/10.1016/j.jpowsour.2017.02.087.

Baudler, A., Schmidt, I., Langner, M., Greiner, A., Schroeder, U., 2015. Does it have to be carbon? Metal anodes in microbial fuel cells and related bioelectrochemical systems. Energy Environ. Sci. 8, 2048-2055. https://doi.org/10.1039/c5ee00866b.

Brown, R.K., Harnisch, F., Wirth, S., Wahlandt, H., Dockhorn, T., Dichtl, N., Schröder, U., 2014. Evaluating the effects of scaling up on the performance of bioelectrochemical systems using a technical scale microbial electrolysis cell. Bioresour. Technol. 163, 206-213. https://doi.org/10.1016/j.biortech.2014.04.044.

Carmona-Martinez, A.A., Trably, E., Milferstedt, K., Lacroix, R., Etcheverry, L., Bernet, N., 2015. Long-term continuous production of H-2 in a microbial electrolysis cell (MEC) treating saline wastewater. Water Res. 81, 149-156. https://doi.org/10.1016/j. watres.2015.05.041.

Chen, S., He, G., Liu, Q., Harnisch, F., Zhou, Y., Chen, Y., Hanif, M., Wang, S., Peng, X., Hou, H., Schröder, U., 2012. Layered corrugated electrode macrostructures boost microbial bioelectrocatalysis. Energy Environ. Sci. 5, 9769-9772. https://doi.org/10. 1039/C2EE23344D.

Chen, J., Xu, W., Wu, X., E, J., Lu, N., Wang, T., Zuo, H., 2019. System development and environmental performance analysis of a pilot scale microbial electrolysis cell for hydrogen production using urban wastewater. Energy Convers. Manag. 193, 52-63. https://doi.org/10.1016/j.enconman.2019.04.060.

Cusick, R.D., Bryan, B., Parker, D.S., Merrill, M.D., Mehanna, M., Kiely, P.D., Liu, G., Logan, B.E., 2011. Performance of a pilot-scale continuous flow microbial electrolysis cell fed winery wastewater. Appl. Microbiol. Biotechnol. 89, 2053-2063. https://doi. org/10.1007/s00253-011-3130-9.

Da Silva, S., Basséguy, R., Bergel, A., 2004. Electrochemical deprotonation of phosphate on stainless steel. Electrochim. Acta 49, 4553-4561. https://doi.org/10.1016/j. electacta.2004.04.039.
Escapa, A., San-Martín, M.I., Mateos, R., Morán, A., 2015. Scaling-up of membraneless microbial electrolysis cells (MECs) for domestic wastewater treatment: Bottlenecks and limitations. Bioresour. Technol. 180, 72-78. https://doi.org/10.1016/j.biortech. 2014.12.096.

Geppert, F., Liu, D., van Eerten-Jansen, M., Weidner, E., Buisman, C., ter Heijne, A., 2016 Bioelectrochemical power-to-gas: state of the art and future perspectives. Trends Biotechnol. 34, 879-894. https://doi.org/10.1016/j.tibtech.2016.08.010.

Gil-Carrera, L., Escapa, A., Carracedo, B., Morán, A., Gómez, X., 2013a. Performance of a semi-pilot tubular microbial electrolysis cell (MEC) under several hydraulic retention times and applied voltages. Bioresour. Technol. 146, 63-69. https://doi.org/10. 1016/j.biortech.2013.07.020.

Gil-Carrera, L., Escapa, A., Mehta, P., Santoyo, G., Guiot, S.R., Moran, A., Tartakovsky, B., 2013b. Microbial electrolysis cell scale-up for combined wastewater treatment and hydrogen production. Bioresour. Technol. 130, 584-591. https://doi.org/10.1016/j. biortech.2012.12.062.

Gil-Carrera, L., Escapa, A., Moreno, R., Moran, A., 2013c. Reduced energy consumption during low strength domestic wastewater treatment in a semi-pilot tubular microbial electrolysis cell. J. Environ. Manag. 122, 1-7. https://doi.org/10.1016/j.jenvman. 2013.03.001.

Grattieri, M., Minteer, S.D., 2018. Microbial fuel cells in saline and hypersaline environments: Advancements, challenges and future perspectives. Bioelectrochemistry 120, 127-137. https://doi.org/10.1016/j.bioelechem.2017.12.004.

Grattieri, M., Suvira, M., Hasan, K., Minteer, S.D., 2017. Halotolerant extremophile bacteria from the Great Salt Lake for recycling pollutants in microbial fuel cells. J. Power Sources 356, 310-318. https://doi.org/10.1016/j.jpowsour.2016.11.090.

Guo, K., Prevoreau, A., Rabaey, K., 2017. A novel tubular microbial electrolysis cell for high rate hydrogen production. J. Power Sources 356, 484-490. https://doi.org/10 1016/j.jpowsour.2017.03.029.

Heidrich, E.S., Dolfing, J., Scott, K., Edwards, S.R., Jones, C., Curtis, T.P., 2013 Production of hydrogen from domestic wastewater in a pilot-scale microbial electrolysis cell. Appl. Microbiol. Biotechnol. 97, 6979-6989. https://doi.org/10.1007/ s00253-012-4456-7.

Heidrich, E.S., Edwards, S.R., Dolfing, J., Cotterill, S.E., Curtis, T.P., 2014. Performance of a pilot scale microbial electrolysis cell fed on domestic wastewater at ambient temperatures for a 12month period. Bioresour. Technol. 173, 87-95. https://doi.org/10. 1016/j.biortech.2014.09.083.

Kadier, A., Simayi, Y., Kalil, M.S., Abdeshahian, P., Hamid, A.A., 2014. A review of the substrates used in microbial electrolysis cells (MECs) for producing sustainable and clean hydrogen gas. Renew. Energy 71, 466-472. https://doi.org/10.1016/j.renene. 2014.05.052.

Ketep, S.F., Bergel, A., Calmet, A., Erable, B., 2014. Stainless steel foam increases the current produced by microbial bioanodes in bioelectrochemical systems. Energy Environ. Sci. 7, 1633-1637. https://doi.org/10.1039/c3ee44114h.

Lee, H.-S., Torres, C.I., Parameswaran, P., Rittmann, B.E., 2009. Fate of H-2 in an upflow single-chamber microbial electrolysis cell using a metal-catalyst-free cathode. Environ. Sci. Technol. 43, 7971-7976. https://doi.org/10.1021/es900204j.

Liu, H., Grot, S., Logan, B.E., 2005. Electrochemically assisted microbial production of hydrogen from acetate. Environ. Sci. Technol. 39, 4317-4320. https://doi.org/10. 1021/es050244p.

Luo, S., Jain, A., Aguilera, A., He, Z., 2017. Effective control of biohythane composition through operational strategies in an innovative microbial electrolysis cell. Appl. Energy 206, 879-886. https://doi.org/10.1016/j.apenergy.2017.08.241.

Marcus, A.K., Torres, C.I., Rittmann, B.E., 2007. Conduction-based modeling of the biofilm anode of a microbial fuel cell. Biotechnol. Bioeng. 98, 1171-1182. https://doi. org/10.1002/bit.21533.

Munoz, L.D., Erable, B., Etcheverry, L., Riess, J., Basséguy, R., Bergel, A., 2010. Combining phosphate species and stainless steel cathode to enhance hydrogen evolution in microbial electrolysis cell (MEC). Electrochem. Commun. 12, 183-186. https://doi.org/10.1016/j.elecom.2009.11.017.

Nam, J.-Y., Logan, B.E., 2012. Optimization of catholyte concentration and anolyte pHs in two chamber microbial electrolysis cells. In: Int. J. Hydrog. Energy, 2011 International Workshop on Molten Carbonates \& Related Topics. 37. pp. 18622-18628. https://doi.org/10.1016/j.ijhydene.2012.09.140.

Oliot, M., Galier, S., Roux de Balmann, H., Bergel, A., 2016. Ion transport in microbial fuel cells: key roles, theory and critical review. Appl. Energy 183, 1682-1704. https://doi.org/10.1016/j.apenergy.2016.09.043.

Oliot, M., Chong, P., Erable, B., Bergel, A., 2017. Influence of the electrode size on microbial anode performance. Chem. Eng. J. 327, 218-227. https://doi.org/10.1016/j cej.2017.06.044.

Pandey, P., Shinde, V.N., Deopurkar, R.L., Kale, S.P., Patil, S.A., Pant, D., 2016. Recent advances in the use of different substrates in microbial fuel cells toward wastewater treatment and simultaneous energy recovery. Appl. Energy 168, 706-723. https:// doi.org/10.1016/j.apenergy.2016.01.056.

Pant, D., Van Bogaert, G., Diels, L., Vanbroekhoven, K., 2010. A review of the substrates used in microbial fuel cells (MFCs) for sustainable energy production. Bioresour. Technol. 101, 1533-1543. https://doi.org/10.1016/j.biortech.2009.10.017.

Parameswaran, P., Torres, C.I., Lee, H.-S., Krajmalnik-Brown, R., Rittmann, B.E., 2009 Syntrophic interactions among anode respiring bacteria (ARB) and non-ARB in a biofilm anode: electron balances. Biotechnol. Bioeng. 103, 513-523. https://doi.org/ 10.1002/bit.22267.

Pocaznoi, D., Calmet, A., Etcheverry, L., Erable, B., Bergel, A., 2012a. Stainless steel is a promising electrode material for anodes of microbial fuel cells. Energy Environ. Sci. 5, 9645-9652. https://doi.org/10.1039/C2EE22429A.

Pocaznoi, D., Erable, B., Etcheverry, L., Delia, M.-L., Bergel, A., 2012b. Towards an engineering-oriented strategy for building microbial anodes for microbial fuel cells. Phys. Chem. Chem. Phys. 14, 13332-13343. https://doi.org/10.1039/C2CP42571H. 
Rimboud, M., Pocaznoi, D., Erable, B., Bergel, A., 2014. Electroanalysis of microbial anodes for bioelectrochemical systems: basics, progress and perspectives. Phys. Chem. Chem. Phys. 16, 16349-16366. https://doi.org/10.1039/c4cp01698j.

Rimboud, M., Desmond-Le Quemener, E., Erable, B., Bouchez, T., Bergel, A., 2015. Multisystem Nernst-Michaelis-Menten model applied to bioanodes formed from sewage sludge. Bioresour. Technol. 195, 162-169. https://doi.org/10.1016/j.biortech.2015. 05.069.

Roubaud, E., Lacroix, R., Da Silva, S., Bergel, A., Basséguy, R., Erable, B., 2018. Catalysis of the hydrogen evolution reaction by hydrogen carbonate to decrease the voltage of microbial electrolysis cell fed with domestic wastewater. Electrochim. Acta 275 , 32-39. https://doi.org/10.1016/j.electacta.2018.04.135.

Rousseau, R., Dominguez-Benetton, X., Délia, M.-L., Bergel, A., 2013. Microbial bioanodes with high salinity tolerance for microbial fuel cells and microbial electrolysis cells. Electrochem. Commun. 33, 1-4. https://doi.org/10.1016/j.elecom.2013.04. 002.

Rousseau, R., Santaella, C., Achouak, W., Godon, J.-J., Bonnafous, A., Bergel, A., Delia, M.-L., 2014. Correlation of the electrochemical kinetics of high-salinity-tolerant bioanodes with the structure and microbial composition of the biofilm. Chemelectrochem 1, 1966-1975. https://doi.org/10.1002/celc.201402153.

Rousseau, R., Rimboud, M., Delia, M.-L., Bergel, A., Basseguy, R., 2015. Electrochemical characterization of microbial bioanodes formed on a collector/electrode system in a highly saline electrolyte. Bioelectrochemistry 106, 97-104. https://doi.org/10.1016/ j.bioelechem.2015.06.011.

Rousseau, R., Santaella, C., Bonnafous, A., Achouak, W., Godon, J.-J., Delia, M.-L., Bergel, A., 2016. Halotolerant bioanodes: the applied potential modulates the electrochemical characteristics, the biofilm structure and the ratio of the two dominant genera. Bioelectrochemistry 112, 24-32. https://doi.org/10.1016/j.bioelechem. 2016.06.006.

Rousseau, R., Etcheverry, L., Roubaud, E., Basséguy, R., Délia, M.-L., Bergel, A., 2020.
Microbial electrolysis cell (MEC): strengths, weaknesses and research needs from electrochemical engineering standpoint. Appl. Energy 257, 113938. https://doi.org/ 10.1016/j.apenergy.2019.113938.

Rozendal, R.A., Hamelers, H.V.M., Euverink, G.J.W., Metz, S.J., Buisman, C.J.N., 2006. Principle and perspectives of hydrogen production through biocatalyzed electrolysis. Int. J. Hydrog. Energy 31, 1632-1640. https://doi.org/10.1016/j.ijhydene.2005.12. 006

Ruiz, Y., Baeza, J.A., Guisasola, A., 2015. Enhanced performance of bioelectrochemical hydrogen production using a pH control strategy. ChemSusChem 8, 389-397. https://doi.org/10.1002/cssc.201403083.

Ruiz, Y., Baeza, J.A., Guisasola, A., 2016. Microbial electrolysis cell performance using non-buffered and low conductivity wastewaters. Chem. Eng. J. 289, 341-348. https://doi.org/10.1016/j.cej.2015.12.098.

San-Martín, M.I., Sotres, A., Alonso, R.M., Díaz-Marcos, J., Morán, A., Escapa, A., 2019. Assessing anodic microbial populations and membrane ageing in a pilot microbial electrolysis cell. Int. J. Hydrog. Energy. https://doi.org/10.1016/j.ijhydene.2019.01. 287.

Selembo, P.A., Merrill, M.D., Logan, B.E., 2009. The use of stainless steel and nickel alloys as low-cost cathodes in microbial electrolysis cells. J. Power Sources 190, 271-278. https://doi.org/10.1016/j.jpowsour.2008.12.144.

Sugnaux, M., Happe, M., Cachelin, C.P., Gasperini, A., Blatter, M., Fischer, F., 2017 Cathode deposits favor methane generation in microbial electrolysis cell. Chem. Eng. J. 324, 228-236. https://doi.org/10.1016/j.cej.2017.05.028.

Torres, C.I., Marcus, A.K., Parameswaran, P., Rittmann, B.E., 2008. Kinetic experiments for evaluating the Nernst-Monod model for anode-respiring bacteria (ARB) in a biofilm anode. Environ. Sci. Technol. 42, 6593-6597. https://doi.org/10.1021 es800970w.

Wendt, H., Kreysa, G., 1999. Electrochemical Engineering: Science and Technology in Chemical and Other Industries. Springer-Verlag, Berlin Heidelberg. 